\title{
Políticas públicas de internacionalização: os cursos de japonês dentro do Idiomas sem Fronteiras
}

DOI: http://dx.doi.org/10.21165/el.v49i3.2566

\section{Daniela Nogueira de Moraes Garcia'}

\section{Resumo}

Considerando as políticas públicas de internacionalização, o programa Idiomas sem Fronteiras ofereceu cursos a instituições de ensino superior e valorizou a formação de professores (SARMENTO; ABREU-E-LIMA; MORAES FILHO, 2016). Os cursos de inglês, espanhol, alemão, francês, japonês e português para estrangeiros atenderam um cronograma nacional. As aulas eram presenciais, mas, segundo especificidades, ocorreram, também, em tempo real, on-line, com o suporte das tecnologias na articulação de contextos importantes. Baseados no potencial das novas tecnologias (COSCARELLI, 2016), com o apoio da Fundação Japão, abordamos o curso on-line de japonês em uma universidade multicampus. Apresentamos a logística desde o treinamento dos professores/tutores, o acompanhamento pedagógico, planejamento, estratégias, divulgação, inscrição e realização do curso. Como resultados, notamos uma demanda existente e antes não atendida por questões geográficas e, também, procedimentos importantes em termos de avaliação e evasão.

Palavras-chave: políticas públicas de internacionalização; língua japonesa; tecnologias.

1 Universidade Estadual Paulista "Júlio de Mesquita Filho" (UNESP), Assis, São Paulo, Brasil; daniela.nm.garcia@unesp.br; https://orcid.org/0000-0003-2813-7538 


\title{
Public Internacionalization policies: the Japanese courses within the Language Without Borders Program
}

\begin{abstract}
Following the public policies of internationalization, the Languages Without Borders Program has offered courses to higher education institutions and valued teacher education (SARMENTO; ABREU-E-LIMA; MORAES FILHO, 2016). English, Spanish, German, French, Japanese and Portuguese for foreigners courses have met a national schedule. Classes were in-person but, regarding specific situations, could take place online, in real-time courses, with the support of technologies in the articulation of important contexts. Based on the potential of the new technologies (COSCARELLI, 2016), and on the support from the Japan Foundation, we approached the on-line Japanese course at a multicampus university. We present the logistics from the training of teachers/tutors, pedagogical supplement, planning, strategies, dissemination, enrollment, and completion of the course. As a result, we note an existing demand that was previously unmet due to geographic issues and also important procedures in terms of assessment and dropout rates.
\end{abstract}

Keywords: public policies of internationalization; Japanese language; technologies.

\section{Introdução}

Os mais diversos setores da sociedade têm sido grandemente impactados pela internet e novas mídias digitais na era atual. Ao potencializar o acesso à informação, permitem um redimensionamento de relações, tempo e espaço como nunca vistos. As experiências e ambientes gerados pelas tecnologias digitais de informação e comunicação (TDICs) alteram cenários e propiciam inclusão e construção de conhecimento. No âmbito educacional, destacamos reconfigurações relevantes em prol das demandas atuais de educadores e aprendizes de forma a fomentar o processo de ensino/aprendizagem.

Em tempos de internacionalização, no cenário das línguas estrangeiras, também, podemos observar que o impacto das TDICs ecoa dentro e fora das salas de aula. As demandas pela inserção e inovação se acentuam frente a ações telecolaborativas e tantas outras que ampliam o acesso às línguas, aos falantes e suas culturas. 
O Ciências sem Fronteiras, programa do Ministério da Educação (MEC) nacionalmente conhecido, abriu portas para a criação do Inglês sem Fronteiras e, em seguida, para o Idiomas sem Fronteiras ${ }^{2}$, como política de incentivo à internacionalização do ensino superior brasileiro. Segundo Sarmento, Abreu-e-Lima e Moraes Filho (2016, p. 11):

O IsF tem proporcionado um terreno fértil para a formação inicial e continuada de professores e para uma constituição de parcerias e de redes. Foi formada uma rede de compartilhamento de informações que hoje une professores de línguas e representantes de Relações Internacionais de centenas de Instituições de Ensino Superior (IES) dos quatro cantos deste nosso imenso país. Todo esse movimento tem resultado em um inevitável e desejável fortalecimento da área do ensino de línguas no Brasil. Os desafios são imensos, mas os resultados colhidos também já são consideráveis, tendo em vista o curto espaço de tempo desde sua implementação.

Assim, pautando-se na visão dos autores acerca das contribuições já vistas e das necessidades de aprendizagem em nossa universidade multicampus e ações expansionistas em diversas regiões no Brasil, como Amazonas, Paraná, Rio Grande do Sul, Distrito Federal e Rio de Janeiro, o Japonês sem Fronteiras (JsF) foi implementado como forma de difundir língua e cultura mundialmente conhecidas pela peculiaridade e fortalecimento em cenário mundial.

A implementação do Idiomas sem Fronteiras (IsF) na UNESP é detalhadamente apresentada por Kaneko-Marques e Garcia (2019) e se constituiu grande passo para a instituição, materializando a preocupação com a melhora da proficiência linguística e, também, com a formação de professores além de impulsionar a construção de uma política de idiomas "[...] buscando atender aos pressupostos da internacionalização do ensino, da pesquisa e da extensão, valorizando as relações interculturais e a inclusão social, tomando como referência a formação integral, o respeito à diversidade e à solidariedade" (KANEKO-MARQUES; GARCIA, 2019, p. 248).

O trabalho aqui exposto aborda especificamente o processo de implementação do curso on-line de japonês na UNESP e, como forma de atender campi geograficamente distantes no estado de São Paulo, agregando o suporte das tecnologias, mídias e aplicativos à oferta de língua japonesa, a partir da descrição das ações realizadas em 2018 e 2019. Para tal finalidade, contextualizamos o papel das tecnologias e mídias digitais no cenário

2 Considerando o panorama nacional instável e recentes cortes governamentais na Educação, o Programa Idiomas sem Fronteiras foi suspenso no segundo semestre de 2019 e, atualmente, encontra-se em fase de remodelação para retomada das atividades. Porém, a oferta de cursos permanece ativa na UNESP a partir de fomento interno ou parcerias/convênios com instituições externas nos diferentes idiomas. 
pedagógico das línguas estrangeiras. Em seguida, enfocamos as ofertas realizadas, presencialmente e sincronicamente à distância da língua japonesa dentro da UNESP e o mapeamento com vistas à oferta de cursos no Programa Japonês sem Fronteiras. Apresentamos, então, os dados coletados e o relato da experiência dos cursos ofertados. Passamos, por fim, aos pontos positivos e, também, desafios a serem superados dentro do cenário apresentado.

\section{As tecnologias no processo de ensino/aprendizagem}

Com o advento das tecnologias, a educação tem sido desafiada e impulsionada a se integrar e promover ações inclusivas e de acesso ao conhecimento. Para Souza e Santos (2019, p. 38), "as novas tecnologias estão adentrando nas escolas e constituindo, assim, um conjunto de oportunidades e desafios para o sistema educacional, propiciando processos de ensino-aprendizagem mais interativos e dinâmicos".

Observamos, dessa forma, a necessidade de um repensar papéis de educadores de modo a atender demandas de uma era globalizada e, também, incluir e se apropriar de tecnologias pelos equipamentos e aplicativos disponibilizados.

As tecnologias digitais, disponíveis agora nos celulares e amplamente utilizadas por todas as camadas sociais como meio de comunicação, produção e disseminação de saberes, precisam ser estudadas e compreendidas. Os mais diversos contextos escolares precisam discutir e se apropriar dessas tecnologias para que os alunos também incorporem em suas vidas as inúmeras possibilidades oferecidas por equipamentos (computadores, laptops, celulares, tablets e outros gadgets) e aplicativos. (COSCARELLI, 2016, p. 11).

Behrens (2013, p. 84) explicita o desafio que se constitui o engajamento de professores e alunos diante de uma atitude crítica e inovadora.

Num mundo globalizado, que derruba barreiras de tempo e espaço, o acesso à tecnologia exige atitude crítica e inovadora, possibilitando o relacionamento com a sociedade. O desafio passa por criar e permitir uma nova ação docente na qual professor e alunos participam de um processo conjunto para aprender de forma criativa, dinâmica, encorajadora e que tenha como essência o diálogo e a descoberta.

O processo conjunto mencionado pela autora se dá como fomento a um processo de aprendizagem que envolve educadores e educandos e possibilita protagonismos múltiplos, tornando tudo mais significativo. Moran (2013, p. 31) vislumbra a escola, com as tecnologias atuais, como "um conjunto de espaços ricos de aprendizagens significativas, 
presenciais e digitais, que motive os alunos a aprender ativamente, a pesquisar o tempo todo, a serem proativos, a saber tomar iniciativas e interagir".

Masetto (2013) reconhece o auxílio prestado pelas novas tecnologias no cenário pedagógico quer presencial quer a distância. O autor destaca aspectos para os quais as tecnologias positivamente apresentam contribuições como dinamização das aulas, vinculação à realidade e conhecimentos produzidos. Em relação ao virtual, afırma que:

Cooperam também, e principalmente, para o processo de aprendizagem a distância (virtual), uma vez que foram criadas para atender a essa nova necessidade e modalidade de ensino. Exploram o uso de imagem, som e movimento simultaneamente, a máxima velocidade no atendimento às novas demandas e o trabalho com as informações dos acontecimentos em tempo real. Colocam professores e alunos trabalhando e aprendendo a distância, dialogando, discutindo, pesquisando, perguntando, respondendo, comunicando informações por meio de recursos que permitem a esses interlocutores, vivendo nos mais longínquos lugares, encontrarem-se e enriquecerem-se com contatos mútuos. (MASETTO, 2013, p. 155).

As necessidades de aprendizagem de língua, no caso aqui enfocado língua japonesa, em contexto de universidade multicampus colocam-se em consonância com os apontamentos do autor. Dessa forma, por meio das conexões à internet, de computadores, celulares e aplicativos, foi possível pensar na oferta de cursos a aprendizes geograficamente dispersos no estado de São Paulo, tornando-os interlocutores no processo de ensino e aprendizagem.

Observamos, assim, que as potencialidades das tecnologias digitais de informação e comunicação (TDIC) perpassam desafios sim, todavia, a possibilidade de maximizar o processo e de conectar professores e alunos, propiciando experiências significativas com a língua estrangeira, permite vislumbrar oportunidades de crescimento, autonomia, competência intercultural, etc.

\section{A construção da trajetória... UNESP e a oferta de cursos on-line: um pouco da metodologia}

A perspectiva qualitativa de cunho etnográfico permeou a coleta e análise dos dados aqui retratados. O processo de implementação dos cursos de japonês em formato síncrono on-line constitui-se ação inovadora e, como tal, explicitamos as etapas e desafios encontrados. 
Informações geográficas se fazem relevantes no contexto que iremos expor para melhor caracterizar nosso cenário de atuação. A configuração espacial da Universidade Estadual Paulista "Júlio de Mesquita Filho" (UNESP) se constitui em multicampus, o que implica em, atualmente, 24 campi espalhados pelo estado de São Paulo, com abrangência desde o litoral até o interior do estado.

São oferecidos mais de 68 cursos a nível de Graduação, sem contabilizar especializações, pós-graduação e projetos de extensão em áreas diversas. Entretanto, sob o grande número, é importante destacar que o curso de Letras (Tradução, Língua Estrangeira e Dupla Habilitação) está disponibilizado em apenas três cidades: Araraquara, Assis e São José do Rio Preto. Tal fato demonstra que a grande maioria dos alunos não possui amplo acesso a cursos de línguas estrangeiras em seu próprio campus, ou, caso tenham, geralmente, são ofertados por meio de projetos e ações de extensão e, muito provavelmente, apenas nas línguas de maior procura, como o inglês e o espanhol.

O campus de Assis tenta atender parte da demanda do ensino/aprendizagem de língua japonesa e se constitui o único, em todo o estado, a oferecer a Licenciatura na referida língua na grade do curso de graduação em Letras. O Centro de Línguas e Formação de Professores que se configura como projeto extensionista, da mesma forma, auxilia, presencialmente, as necessidades e oferta de cursos de japonês a vários níveis para comunidades interna e externa.

Associada à questão de ser o único campus, retomamos a configuração multicampus que dificulta o acesso à língua japonesa. Por outro lado, observamos, ainda, que há vários acordos internacionais estabelecidos entre a UNESP e instituições no Japão para o desenvolvimento de pesquisas em distintas áreas do conhecimento. Dessa forma, comprovamos a necessidade de aprendizagem da língua japonesa em toda a comunidade unespiana e, a partir daí, começamos a cogitar o acesso à língua e cultura.

Diante do exposto, a Coordenação Geral do IsF autorizou a UNESP a conduzir cursos online aos campi não atendidos pelos cursos de Letras de forma bastante monitorada a fim de acompanhar, detalhadamente, o andamento das atividades síncronas realizadas em ambiente virtual a aprendizes geograficamente distantes.

Assim, sob o formato síncrono on-line, os cursos à distância foram ministrados em tempo real, permitindo atenção às necessidades de proficiência linguística e, também, aplicação de exames de proficiência internacionais, no caso do inglês, por exemplo. Acima de tudo, destacamos o acesso bastante democrático às línguas e suas culturas.

Observamos, assim, que a UNESP foi (eainda está) adquirindo expertise para ofertar cursos on-line nas variadas línguas, com primazia e qualidade. Uma preocupação pedagógica se 
instaurou de modo a realizar ações de acompanhamento e frequente orientação para os professores/tutores para atuação no ambiente virtual. Tais procedimentos se mostraram de extrema relevância nas avaliações dos cursistas do JsF, como abordaremos aqui, que puderam observar o preparo dos professores na condução dos cursos on-line.

A partir da oferta de cursos on-line e da observação do processo de implementação do JsF, sob aconselhamento da Coordenação Geral do IsF, tornou-se necessária a elaboração de um Protocolo de Letramento Digital (Anexo 1) como forma de orientar os alunos cursistas, evitar situações desagradáveis e maximizar o processo de ensino/aprendizagem de línguas estrangeiras em tal modalidade de cursos. O Protocolo esclarece procedimentos das aulas e de conduta pessoal e, também, apresenta instruções tecnológicas sendo introduzido aos alunos cursistas pelo Coordenador Pedagógico ou pelo professor/tutor no primeiro contato com a turma. O presente Protocolo deverá ser utilizado como padrão para todos os cursos on-line ministrados no contexto da UNESP.

\section{UNESP e a Língua Japonesa}

O credenciamento da UNESP no Programa Idiomas sem Fronteiras para a integração da língua japonesa se deu em 2017. Com o imprescindível suporte da Fundação Japão, no que diz respeito ao respaldo pedagógico com a cessão do material didático e orientação para seu manuseio e, também, financeiro com as bolsas das tutoras e da coordenação, o processo de implementação foi inicializado. Como primeira ação, a proposta foi consolidada de forma presencial para atender ao calendário nacional de ofertas disponibilizado pelo IsF. Como a demanda já é suprida localmente, conforme explanado anteriormente, em Curso de Graduação e cursos do Centro de Línguas, deparou-se, neste formato, com o desafio da constituição de turmas presenciais diante das 25 vagas disponibilizadas.

Assumimos a coordenação do Japonês no segundo semestre de 2018 após a supracitada tentativa de oferta de curso presencial. Considerando nossa expertise com os cursos síncronos on-line ofertados via Zoom ${ }^{3}$ pelo Inglês sem Fronteiras, objetivamos implementar o mesmo formato e tentar suprir necessidades na língua japonesa dentro da UNESP, multicampus.

3 Aplicativo para realização de videoconferências. Para maiores informações: https://zoom.us/ 
Para melhor caracterizar o cenário de ensino/aprendizagem de língua japonesa no Brasil, apenas seis instituições de Ensino Superior ${ }^{4}$ oferecem tal língua na Graduação e, também, pelo programa Japonês sem Fronteiras. A UNESP, todavia, constitui-se pioneira ao realizar oferta de curso on-line, como descreveremos a seguir.

No segundo semestre de 2018, foi realizada oferta do curso "Língua Japonesa em Contexto Acadêmico: começando a vida no Japão", com nível A1 (iniciante) conforme o quadro comum de referência europeu, e com carga horária de 48 horas, divididas em dois encontros semanais de duas horas cada. Esse curso foi disponibilizado, especificamente, para o Instituto de Biociências de Botucatu, campus escolhido pelos acordos de cooperação mantidos com o Japão. Esse foi considerado piloto (Piloto 1) dado o formato síncrono online, no qual cada cursista poderia realizar as aulas de um local de sua escolha desde que garantida uma boa conexão à internet. Por motivos de comunicação pouco eficiente e pouca habilidade de gerenciamento de inscrições no sistema do Ministério da Educação, deparamo-nos com uma tímida divulgação e um resultado final de 18 inscrições para as 25 vagas disponibilizadas.

Como nos demais cursos ministrados no IsF, quer formato presencial, quer on-line, a evasão foi detectada e, apenas, cinco dos 18 inscritos concluíram o módulo com presença e participação nas aulas ministradas e desempenho satisfatório nas avaliações.

Como parte das ações de incentivo da Fundação Japão, dois desses cursistas concluintes, que se destacaram nas avaliações, contribuições e envolvimento no decorrer do módulo, participaram de um processo seletivo nacional dentre todos os cursistas do JsF e foram contemplados com um curso no Japão. As despesas foram custeadas e a viagem pensada como forma de fomentar experiências linguísticas e culturais, mediante fomento da FJ. As imagens 1 e 2 apresentam, com anonimato, os dois estudantes da UNESP que embarcaram em julho de 2019 para a viagem de 15 dias ao Japão. A imagem 1 retrata os dois estudantes na preparação para a viagem e a imagem 2 retrata um dos estudantes com a coordenadora pedagógica no Japão, na cerimônia de formatura.

4 Universidade Federal do Amazonas (UFAM), Universidade Federal do Paraná (UFPR), Universidade Federal do Rio de Janeiro (UFRJ), Universidade de Brasília (UnB), Universidade Federal do Rio Grande do Sul (UFRS) e Universidade Estadual Paulista "Júlio de Mesquita Filho" (UNESP). 
Imagens 1 e 2. Estudantes da UNESP contemplados com curso no Japão (Piloto 1)
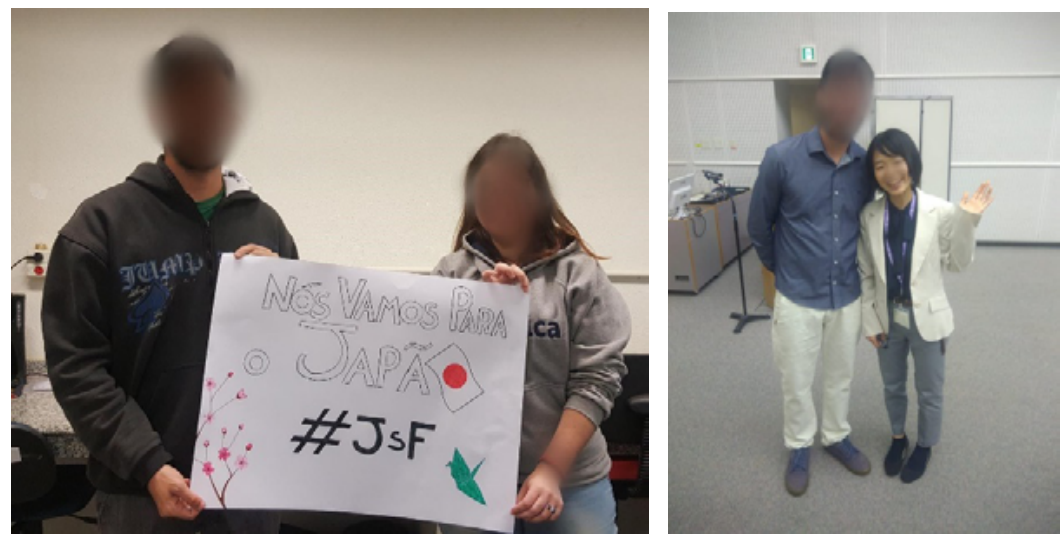

Fonte: Acervo pessoal

Os cursos oferecidos sempre nos sinalizam pontos de sucesso e pontos a serem aprimorados, permitindo, também, uma sondagem de demanda e mapeamento de dados para ações futuras. Após orientação do Núcleo Gestor e da Coordenação de Japonês do IsF, decidimos o formato da oferta seguinte de curso on-line para o primeiro semestre de 2019 (Curso 1), definindo um polo Sede, estabelecido no campus de Assis, e transmissão/ acesso simultâneo para demais polos.

Com o pronto suporte e mediação da Assessoria de Relações Externas (AREX) da UNESP, as unidades foram consultadas acerca do interesse/disponibilidade para estabelecerem Pólos do curso on-line. Retornaram, de forma positiva e ágil, sediados em Araraquara, São José do Rio Preto, Franca, Marília e Botucatu. Assim, comprometeram-se a receber o curso em suas instalações, garantindo a acessibilidade à internet e aos computadores de laboratórios de informática.

A partir daí, o processo de divulgação foi iniciado, incluindo informações sobre o curso e período de inscrição. Para tal, e-mails institucionais foram enviados e grupos do Facebook foram acessados por meio de publicações. Uma vez abertas as inscrições, estudantes de graduação, pós-graduação, docentes e funcionários técnico-administrativos dos seis polos estavam aptos a realizarem cadastro no sistema do MEC e buscarem o curso de interesse.

Com o recebimento de 142 inscrições, extrapolando o limite de uma turma (25 alunos), a situação foi apresentada à FJ que, com muita compreensão e solicitude, ofereceu-nos uma bolsa extra para contratação de mais um tutor. Dessa forma, duas turmas puderam ser disponibilizadas para que, ao menos, 50 cursistas fossem atendidos na oferta. A evasão, que merece um estudo, foi detectada nessa edição, também, e 18 e 15 alunos, respectivamente, em cada turma finalizaram o Curso 1. 
o Curso 1 abordou o mesmo conteúdo ministrado no Piloto 1. As atividades avaliativas incluíram provas orais, de escuta e escrita e abordaram temas estudados no decorrer das aulas com utilização da plataforma Google Forms.

Avançando nos procedimentos, dois questionários semiestruturados foram enviados aos cursistas, designados Q1 e Q2 para melhor elucidação, aqui. O primeiro questionário foi elaborado pela coordenadora do curso em parceria com as professoras tutoras e foi disponibilizado on-line, via Google Forms. 20 questões foram apresentadas com o intuito de obter, junto aos cursistas, informações acerca do desempenho das professorastutoras, do acesso à internet, do apoio dos campi inscritos no programa, dentre outros aspectos. O segundo questionário foi enviado, em japonês, diretamente pela FJ e contou com o auxílio das professoras-tutoras para intermediar sua aplicação e devolução, já que era necessária a assinatura dos cursistas respondentes, demandando impressão e escaneamento. Com sete perguntas, o Q2 focava nos motivos pelos quais os cursistas optaram pelo curso, como interesse pela cultura pop japonesa (animês, mangás, músicas, filmes, etc.), a presença da língua japonesa em suas famílias, o desejo e/ou necessidade de usar o japonês no ambiente de trabalho, entre outras.

O Curso 2 foi ofertado em julho de 2019. Sua estrutura foi elaborada em Reunião de Coordenadores do JSF no primeiro semestre de 2019 e apresentou o caráter inovador de sua carga horária, 16 horas. Optamos por deixá-lo disponível a toda a comunidade unespiana no estado de São Paulo e, considerando o período de férias, de permitir o acesso de um local de escolha do próprio cursista. Para uma turma de 25 cursistas, foram recebidas 42 inscrições.

O Curso 3, de 48 horas, como ministrado anteriormente, encerrou o processo de inscrição pelo sistema do MEC com 134 interessados mediante as 50 vagas disponibilizadas. Como no Curso 2, foi disponibilizado para toda a comunidade unespiana e, também, com acesso autorizado de qualquer computador com boa conexão à internet.

Para melhor compreensão, a figura 1 contempla os cursos e a trajetória de implementação do JsF na UNESP. 
Figura 1. Trajetória do JsF na UNESP

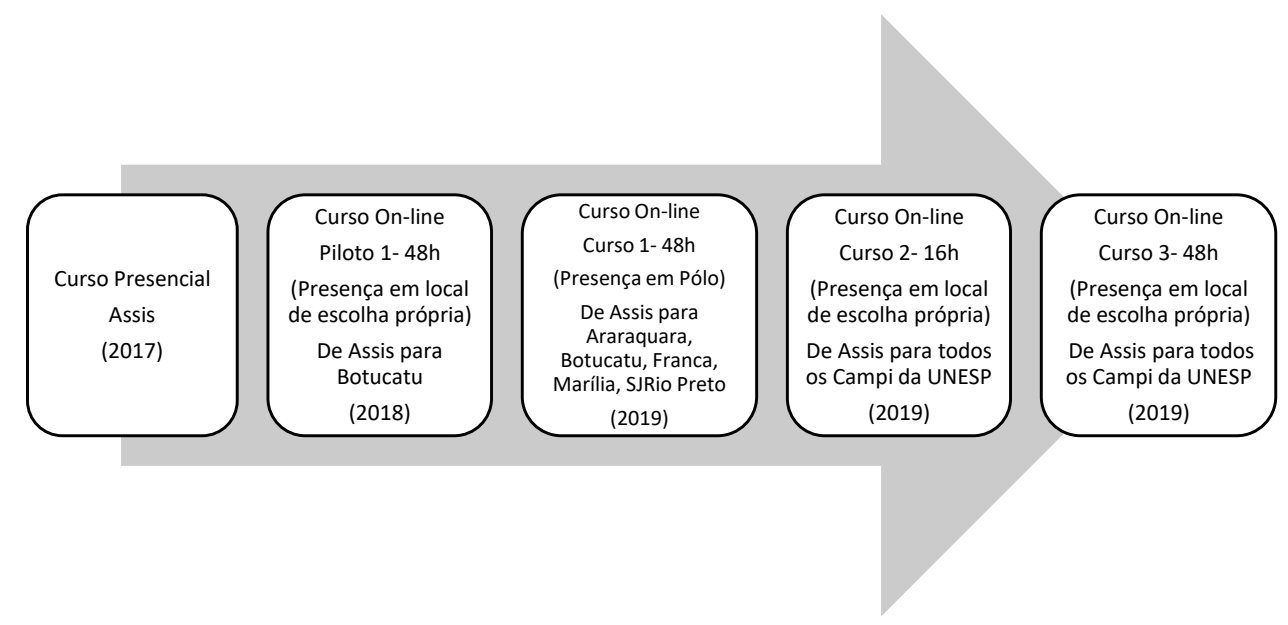

Fonte: Elaboração própria

\section{Compartilhando dados}

Retratamos, nesta seção, dados referentes ao Curso 1 visto que sua articulação se deu de forma bastante robusta, mas, trazemos, também, dados referentes ao Piloto 1 por acreditar que ambos participam da trajetória de implementação dos cursos de japonês na UNESP. Da mesma forma, ambos sinalizam questões de relevância no que diz respeito a desafios e avanços para ofertas futuras.

Como explicitado, o polo sede para o curso foi a Faculdade de Ciências e Letras - UNESP - Assis, onde as tutoras fisicamente se encontravam, no laboratório, e de onde as aulas eram ministradas e acessadas por cursistas geograficamente distantes.

Figura 2. Polo sede
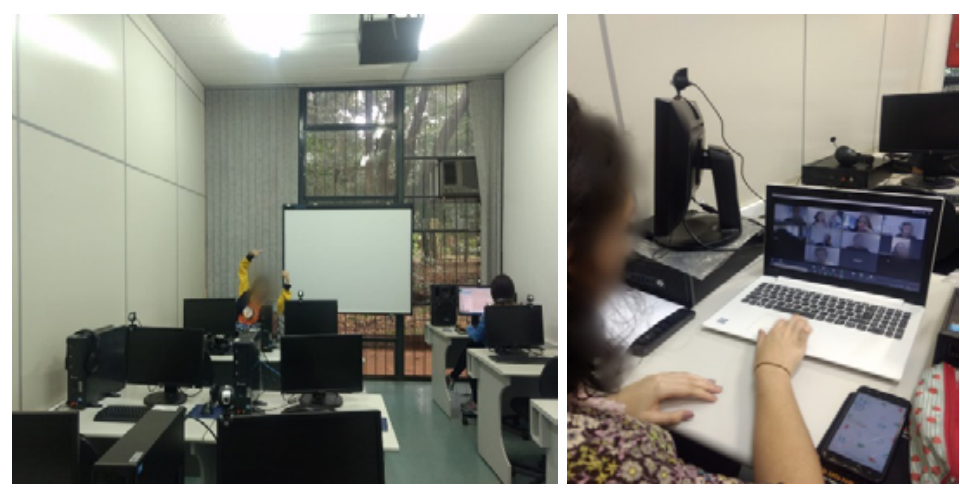

Fonte: Acervo pessoal 
A figura 3 retrata diferentes momentos da tela do computador durante uma aula do Curso On-line de Japonês, Curso 1, que foi ministrado no primeiro semestre de 2019. 0 aplicativo de videoconferência é o Zoom dadas importantes especificidades como o limite de até cem pessoas on-line simultaneamente e dispositivos importantes como divisão dos cursistas em grupo, compartilhamento de tela, recursos de gravação de áudio e vídeo, dentre outros.

Figura 3. Aula do Curso On-line de Japonês - Curso 1
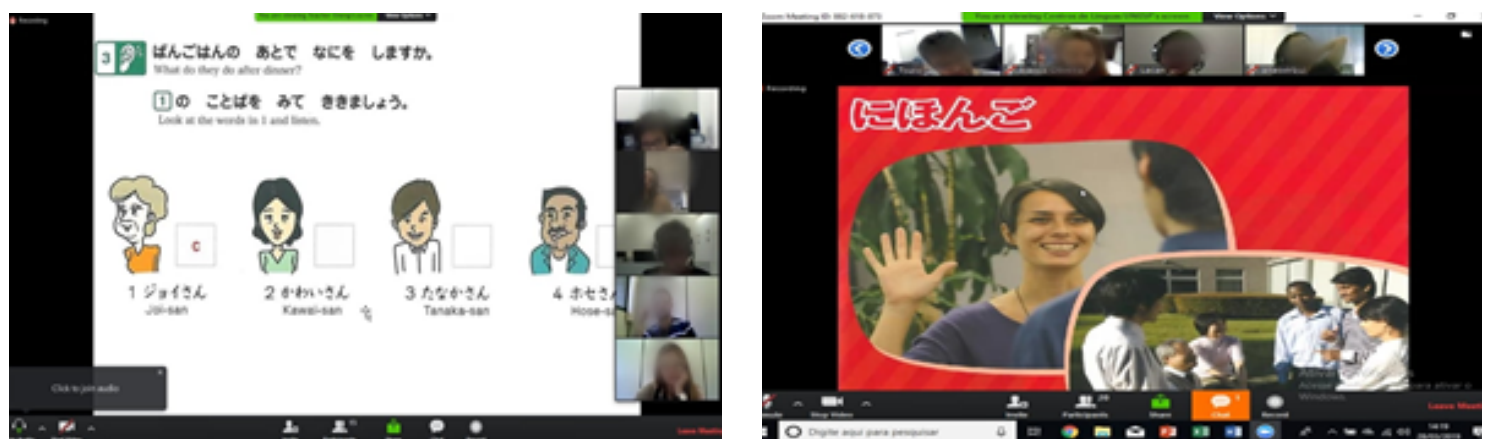

Fonte: Acervo pessoal

Os questionários, diários e relatos elaborados pelas professoras tutoras constituem-se instrumentos de coleta de dados.

Tabela 1. Números do Curso 1

\begin{tabular}{cccccc}
\hline Turma & $\begin{array}{c}\text { Total de } \\
\text { horas }\end{array}$ & $\begin{array}{c}\text { Número } \\
\text { de alunos } \\
\text { iniciais }\end{array}$ & $\begin{array}{c}\text { Número } \\
\text { de alunos } \\
\text { concluintes }\end{array}$ & $\begin{array}{c}\text { Questionários a } \\
\text { serem respondidos }\end{array}$ & $\begin{array}{c}\text { Número total } \\
\text { de alunos que } \\
\text { responderam o } \\
\text { questionário }\end{array}$ \\
\hline $\mathbf{1}$ & $48 h$ & 25 & 18 & 2 (on-line e físico) & 33 \\
\hline $\mathbf{2}$ & $48 \mathrm{~h}$ & 25 & 15 & 2 (on-line e físico) & \\
\hline
\end{tabular}

Fonte: Elaboração própria

Agora, compartilhamos dados dos supracitados instrumentos que nos auxiliam a melhor compreender o cenário do curso on-line e os desafios encontrados. Para tanto, recortes foram feitos nos dados.

A pergunta abaixo, de número 8, questionou se era a primeira experiência dos cursistas em curso on-line síncrono. 
Gráfico 1. Porcentagem de primeiro curso on-line síncrono- Curso 1

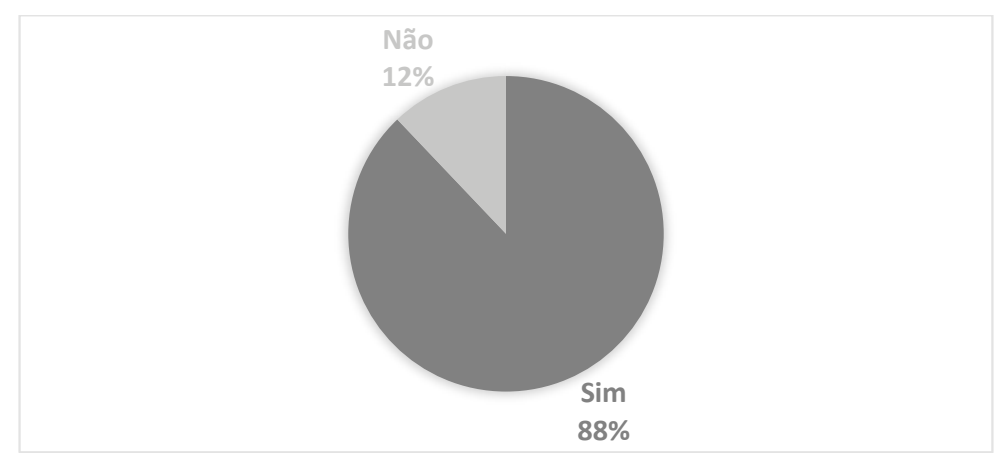

Fonte: Elaboração própria

Dos 33 respondentes, 29 afirmaram se tratar do primeiro curso on-line síncrono a participarem. As recorrentes ofertas de cursos do IsF apontam para uma compreensão ainda não muito clara, apesar dos grandes esforços de divulgação, para a configuração dos cursos on-line que muito se diferenciam de diversas ações de Educação à Distância desenvolvidas até o início de 2020 em nosso país ${ }^{5}$. A presença do tutor, o formato síncrono de aula e as variadas possibilidades do aplicativo constituem-se diferenciais e são vistos de forma positiva pelos cursistas, como veremos adiante.

Sobre a avaliação das aulas, os cursistas demonstraram uma visão bastante favorável, com 26 classificando-as como "muito satisfatórias" e apenas um como "mediana".

Gráfico 2. Porcentagem de avaliação das aulas - Curso 1

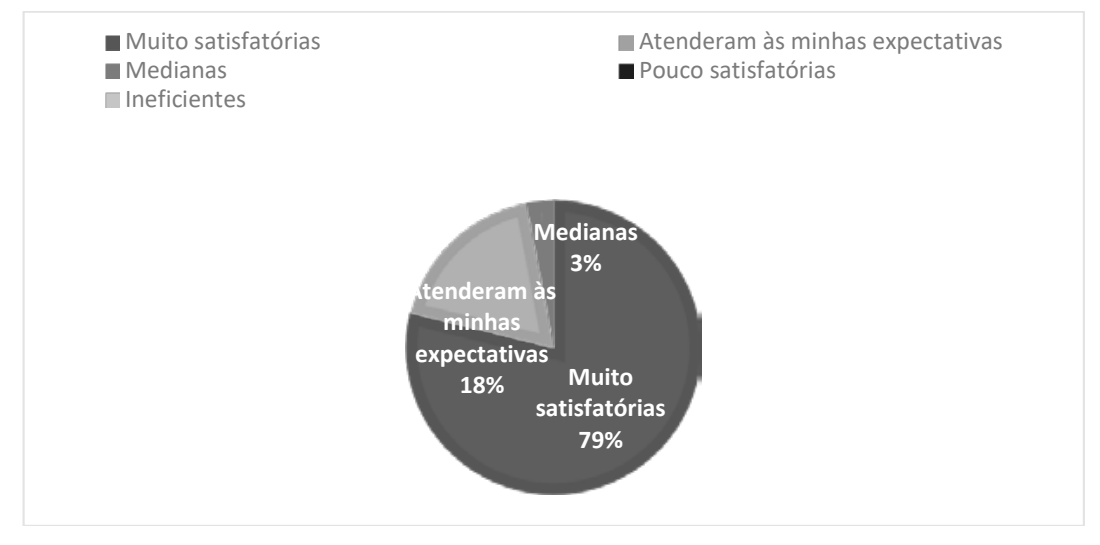

Fonte: Elaboração própria

5 De março de 2020 em diante, considerando a pandemia do COVID-19, o cenário pedagógico e as ações a distância sofreram grandes alterações, mas, por motivos de foco, não serão abordadas no presente estudo. 
Quando questionados acerca dos pontos negativos e positivos das aulas, os cursistas expuseram questões relacionadas à internet, ao material didático, à carga horária, ao comprometimento das tutoras, à interação, entre outras. Selecionamos alguns excertos que retratam os comentários dos cursistas em relação ao curso on-line.

Quadro 1. Pontos positivos e/ou negativos das aulas - Curso 1

\begin{tabular}{|l|l|}
\hline Cursista Z & $\begin{array}{l}1 \text { O curso mal parece que é on-line de tão efetivo. A professora é ótima, aborda todas } \\
2 \text { as duvidas de forma muito clara, e passa o conteúdo (que é um pouco difícil) da } \\
3 \text { melhor forma para a nossa compreensão e incentivando sempre o dinamismo da aula } \\
4 \text { em prol do processo de aprender de verdade. }\end{array}$ \\
\hline Cursista J & $\begin{array}{l}5 \text { As aulas são ótimas para o período de tempo de curso proposto. Apesar de não } \\
6 \text { abranger uma grande grade horária como cursos de idiomas presenciais, os } \\
7 \text { conteúdos ensinado neste curto período de tempo é essencial para a aprendizagem } \\
8 \text { do nível básico do idioma, além da alta qualidade do material disponibilizado pela } \\
9 \text { fundação, e a gratuidade do curso. Contudo, acho que seria interessante que o } \\
10 \text { material incorporasse mais elementos gramáticos, mesmo nesse nível básico. }\end{array}$ \\
\hline
\end{tabular}

Fonte: Elaboração própria

Como podemos observar, a adaptação ao formato levou o cursista $Z$ a afırmar que " 0 curso mal parece que é on-line de tão efetivo" (linha 1). A tutora e seu comprometimento são, também, mencionados. Destacamos a importância do professor para atuação em contextos on-line. Não se trata de fácil missão, mas o engajamento, atenção às necessidades, articulação de um ambiente tranquilo à aprendizagem são imprescindíveis no papel do educador frente às demandas tecnologizadas.

O cursista J reconhece a positiva relação entre o curso/conteúdo/material didático/carga horária. Destaca, ainda, a gratuidade do curso como fator positivo. Ressalta, porém, sua necessidade de aprofundamento em elementos gramaticais ao nível ensinado. É bastante interessante notar na avaliação dos cursistas a relevância das questões elencadas, o que denota comprometimento para com o curso que, apesar de gratuito e on-line como vários poderiam frisar, atende as necessidades de maneira satisfatória.

Questões relacionadas à queda de internet e entraves com dispositivos para a participação nas aulas, no Curso 1, foram recorrentes, como sinalizaram 13 dos cursistas que concluíram o curso. As porcentagens estão demonstradas no gráfico 3. 
Gráfico 3. Porcentagem de cursistas com problemas de ordem tecnológica - Curso 1

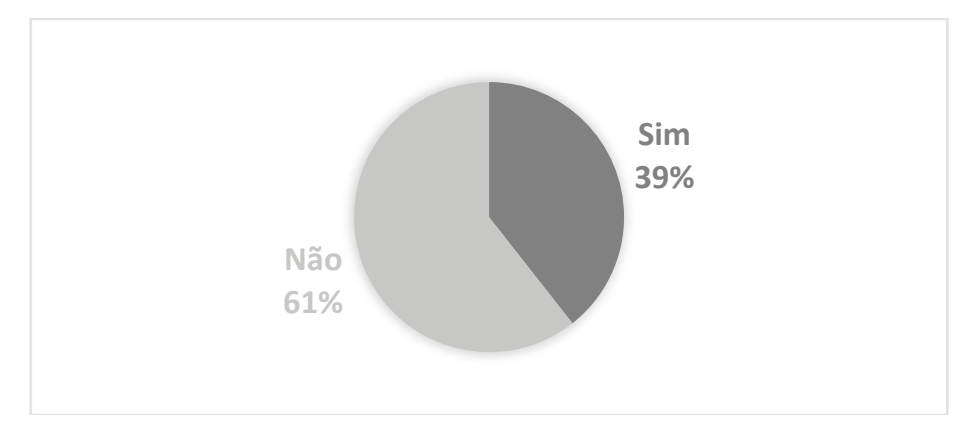

Fonte: Elaboração própria

Como a presença nos polos era obrigatória no Curso 1, questões de ordem tecnológica poderiam demandar tempo para serem solucionadas, quando possível. A imprevisibilidade era, assim, recorrente já que, por exemplo, a internet na universidade é administrada por um órgão interno, podendo sofrer intercorrências pela demanda de usuários em uma mesma rede, questão essa que pode não ser resolvida com a extrema agilidade, considerando a disponibilidade de servidores e um curso on-line com horário de início e término.

Entretanto, por mais que tenha havido entraves, a maioria dos alunos constatou que não foram barreiras capazes de impedir o andamento das aulas.

Em relação ao segundo questionário, já mencionado, elaborado pela FJ com enfoque no interesse em relação ao curso, as respostas apontaram que a maioria dos cursistas apontou interesse pela própria língua japonesa em si própria, além de interesse pela cultura, história, literatura, arte do Japão. Sinalizaram, ainda, interesse no curso com a finalidade de estudar no Japão, prestar exames ou obter certificados em língua japonesa e a compreensão internacional e intercâmbio em geral entre diversas culturas. As respostas compiladas pelo Q2 reúnem informações interessantes no que diz respeito ao perfil do cursista e as razões que o motivam a participar da oferta de curso. Destacamos alguns excertos que retratam comentários elaborados por alguns cursistas no intuito de registrar sua visão. O comentário no quadro 2 registra uma trajetória de conexão estabelecida com a língua "desde pequeno" (linha 1). 
Quadro 2. Comentário suplementar no Q2 - Curso 1

\begin{tabular}{|l|l|}
\hline Cursista V & 1 Porque desde pequeno meus pais tinham amigos descendentes de japoneses \\
2 que se comunicavam na língua nativa, e eu ficava muito intrigado. \\
3 Enquanto cursei o colegial estudei um pouco da língua por conta com \\
4 materiais didáticos que ganhei dos amigos dos meus pais e com um \\
5 dicionário que comprei. Cheguei a fazer também 3 anos de mandarim \\
6 enquanto estava no colegial pelo Instituto Confúcio para ter uma maior \\
7 aproximação dos kanji. E o curso de japonês sendo ofertado de graça, e \\
8 sendo uma língua que sempre tive interesse, resolvi participar.
\end{tabular}

Fonte: Elaboração própria

Percebemos, também, no excerto do cursista $V$, uma trajetória de interesse de estudo da língua japonesa em momentos e contextos variados. Reconhecemos, assim, a grandiosidade do curso on-line que, além de gratuito, pode alcançar e incluir cursistas interessados e dispostos, independentemente de onde estejam geograficamente. 0 comentário registrado no quadro 2 registra uma trajetória de conexão estabelecida com a língua "desde pequeno" (linha 1).

O quadro 3 retrata excerto que abrange avaliação das aulas, do conteúdo e uma autoavaliação do cursista.

Quadro 3. Comentário suplementar no Q2 - Curso 1

\begin{tabular}{|l|l|}
\hline Cursista A & 1 Todas as aulas foram muito enriquecedoras, tanto a maneira como o \\
& 2 conteúdo foi ministrado como os diálogos sobre a cultura japonesa. Sinto \\
& 3 que compreendi todo o conteúdo e que já seria capaz de estabelecer alguns \\
& 4 diálogos com uma pessoa de origem japonesa. \\
\hline
\end{tabular}

Fonte: Elaboração própria

Destacamos a percepção do cursista em relação à "cultura japonesa" (linha 2) e da aprendizagem que expande os conteúdos com vistas ao desenvolvimento da competência linguística e intercultural (linhas 3 e 4).

Por fim, buscamos a voz das professoras tutoras participantes do Curso 1 do JsF, mais especificamente, a respeito de suas experiências durante os 15 dias de treinamento de professores realizado em janeiro de 2019, no Instituto Internacional de Kansai, OsakaJapão, fomentados pela FJ.

De acordo com a tutora: 
Quadro 4. Relato de tutora 1 - Curso 1

\begin{tabular}{|l|l|}
\hline Tutora 1 & $\begin{array}{l}1 \text { Nós pudemos fazer parte das mais diversas atividades, além das aulas com } \\
2 \text { enfoque especial para aspectos da cultura do cotidiano no Japão. Além, } \\
3 \text { disso, foi possível que descobríssemos o país e sua cultura de forma única } \\
4 \text { e individual, por meio de nossa própria vivência durante os quinze dias de } \\
5 \text { treinamento. }\end{array}$ \\
\hline
\end{tabular}

Fonte: Elaboração própria

Assim, por meio do treinamento e das aulas, as professoras tutoras foram inseridas em diversos aspectos culturais da sociedade japonesa e, por meio deles, tornaram-se capazes de aplicar tais conhecimentos em suas aulas, revendo conceitos teórico-metodológicos e unindo-os à prática vivenciada no Japão. Segundo a tutora 2, ambas tiveram:

Quadro 5. Relato de tutora 2 - Curso 1

\begin{tabular}{l|l} 
Tutora 2 & $1[. .$.$] a chance de desenvolver nossas habilidades na língua japonesa ao$
\end{tabular} 2 mesmo tempo em que entrávamos em contato direto com situações e 3 práticas muito presentes no dia-a-dia e na cultura do país, o que, sem 4 dúvida, serão de grande valia para as aulas de japonês no Brasil.

Fonte: Elaboração própria

Além das práticas individuais, as professoras, tutoras 1 e 2, também, tiveram a oportunidade de aprimorar sua proficiência linguística, uma vez que estavam em contato direto com a língua estrangeira, inseridas em língua, cultura e país. No Q2 que, também, tiveram que preencher, a tutora 1 destaca:

Quadro 6. Comentário suplementar no Q2 - Curso 1

\begin{tabular}{|l|l|}
\hline Tutora 1 & 1 Por conta de as aulas serem on-line, tive que rever e aprender a construir \\
& 2 novas metodologias de ensino. Durante os encontros, procurava aprender \\
3 os ideais e os costumes dos alunos também, ao invés de só mostrar o meu \\
4 ponto de vista e/ou o do livro didático. Aprendi muito sobre as cidades dos \\
5 estudantes, suas famílias, tradições, etc. Por isso, acredito que seja possível \\
6 conectar-se com os estudantes por meio do livro didático e das aulas.
\end{tabular}

Fonte: Elaboração própria

Após olhar para os dados, compreendemos que as ações aqui descritas perpassam as línguas, as culturas, a formação de professores, novas tecnologias, novas demandas, desenvolvimento de competência linguística e intercultural, etc. Cada uma dessas poderia se constituir um novo viés para enfocar os cursos de japonês oferecidos dada a riqueza 
de informações a compartilhar. Todavia, neste momento, voltamo-nos aos processos de implementação.

Passamos, assim, aos comentários finais a partir do cenário descrito no presente estudo.

\section{Considerações finais}

Ações que fomentem a inclusão, o desenvolvimento de uma postura crítico-reflexiva e de competência intercultural devem compor o cenário educacional das línguas estrangeiras diante de uma sociedade tecnologizada. Carecemos de políticas públicas humanizadoras e que, de fato, atendam às necessidades emergentes de ensino/aprendizagem.

O processo de implementação do Curso On-line de Japonês em instituição multicampus aqui descrito almeja, de fato, abrir caminhos e articular contextos para que a língua japonesa, com toda sua riqueza linguística e cultural, seja oferecida de forma robusta e acessível.

A parceria firmada junto à Fundação Japão impacta o cenário de ensino e aprendizagem da língua, promovendo a oferta de cursos e o crescimento em diversas esferas, além de detectar uma demanda emergente e fomentar o interesse. Retomamos ações de primordial importância no processo de implementação aqui já abordadas: (a) a cessão do material didático e o suporte pedagógico semanalmente oferecido às professoras tutoras, (b) o investimento financeiro destinado à coordenação e, também, às referidas professoras de acordo com os cursos ministrados, (c) o acompanhamento de todas atividades realizadas no JsF, (d) os cursos gratuitamente oferecidos no Japão às professoras tutoras como forma de imersão e aperfeiçoamento linguístico e cultural e, por fim, (e) os cursos gratuitamente oferecidos no Japão, mediante processo seletivo a concluintes que se destacaram.

Destacamos o relevante papel das professoras tutoras dos cursos ministrados no JsF na UNESP para o bom andamento das atividades e para a construção da trajetória aqui descrita. Apesar de não apresentarem grandes treinamentos para atuação no contexto on-line, com o suporte pedagógico da FJ e da equipe do ISF na UNESP o fizeram com excelência.

Concluímos o presente trabalho com a compreensão de que o Piloto 1 e os cursos ofertados possibilitaram a visualização de que, com esforços e articulações, é possível detectar demandas e alcançar objetivos envolvendo educadores e educandos e o contexto da língua japonesa. Mostraram, ainda, que há diversos desafios a serem superados como, por exemplo, questões tecnológicas. Esperamos, todavia, que as ações aqui descritas proporcionem amadurecimento e melhorias em próximas versões e ofertas com vistas a contribuições para o cenário da oferta de cursos de línguas estrangeiras no Brasil. 


\section{REFERÊNCIAS}

BEHRENS, M. A. Projetos de aprendizagem colaborativa num paradigma emergente. In: MORAN, J. M. et al. (org.). Novas tecnologias e mediação pedagógica. Campinas: Papirus, 2013. p. 73-140.

COSCARELLI, C. V. Navegar e ler na rota do aprender. In: COSCARELLI, C. V. (org.) Tecnologias para aprender. São Paulo: Parábola Editorial, 2016. p. 11-14.

KANEKO-MARQUES, S. M.; GARCIA, D. N. M. Implementação do Programa Idiomas sem Fronteiras na UNESP. Revista Estudos Linguísticos, v. 48, n. 1, p. 242-261, abr. 2019.

MASETTO, M. T. Mediação pedagógica e tecnologias de informação e comunicação. In: MORAN, J. M. et al. (org.). Novas tecnologias e mediação pedagógica. Campinas: Papirus, 2013. p. 141-171.

MORAN, J. M. Ensino e aprendizagem inovadores com apoio de tecnologias. In: MORAN, J. M. et al. (org.). Novas tecnologias e mediação pedagógica. Campinas: Papirus, 2013.

p. 11-72.

SARMENTO, S.; ABREU-E-LIMA, D. M.; MORAES FILHO, W. B. (org.). Do Inglês sem Fronteiras ao Idiomas sem Fronteiras: a construção de uma política linguística para internacionalização. Belo Horizonte: Editora UFMG, 2016.

SOUZA, F. M.; SANTOS, G. F. Velhas práticas em novos suportes? As tecnologias digitais como mediadoras do complexo processo de ensino-aprendizagem de línguas. São Paulo: Mentes Abertas, 2019. 


\section{ANEXO - PROTOCOLO DE LETRAMENTO DIGITAL}

Olá,

Para participar de cursos síncronos on-line, é necessário que tenha a plena compreensão acerca de algumas questões de grande pertinência a fim de que sua experiência, na sala de aula virtual, seja bem-sucedida.

Passamos, então, às supracitadas questões.

1. O que é um curso síncrono on-line?

Um curso síncrono on-line é ministrado em ambiente virtual com aulas em tempo real. Não são aulas gravadas e, dessa forma, não poderão ser repostas. Seu professor estará on-line, ao mesmo tempo que você, para ministrar a aula.

\section{O que é uma sala de aula virtual?}

Uma sala de aula virtual corresponde a uma sala de aula mesmo. Podemos diferenciar o presencial do virtual, pensando que o virtual se constitui com o suporte do contexto tecnológico. Os cursos on-line são oferecidos como em contexto de sala de aula, ou seja, não pense que os direitos/deveres serão diferentes apenas se considerarmos um suporte diferente (presencial/virtual)

3. Qual é o aparato tecnológico necessário para que eu participe de um curso síncrono on-line?

Você vai precisar de um computador com webcam e microfone e uma conexão à internet estabilizada. TODOS os itens destacados são imprescindíveis para participar de um curso síncrono on-line. Há muitas coisas que são pensadas quando da articulação desses cursos, como aspectos interacionais necessários em cursos de idiomas, sincronicidade, a linguagem corporal. Lembramos, mais uma vez, que em um curso síncrono on-line, você integra uma sala de aula.

\section{O que devo fazer diante de um computador?}

É necessário que você esteja bem posicionado com a câmera em seu rosto. Dessa forma, seu professor poderá fazer a leitura de sua produção linguística, suas expressões faciais de dúvida, compreensão, da mesma forma como seus colegas de turma. 


\section{Como acessar um curso síncrono on-line?}

Os cursos síncronos on-line são ministrados via aplicativo ZOOM. Para ter acesso às aulas, você receberá um link de seu professor e precisará estar logado em seu computador. Isso significa que você estará on-line, locado em uma sala de aula virtual, para participar da aula, em tempo real, juntamente com seu professor e colegas de curso.

\section{As aulas são gravadas?}

Algumas aulas poderão ser gravadas, mas não disponibilizadas a cursistas. O propósito das gravações é didático-pedagógico. As aulas podem ser enviadas a professores/ educadores/coordenadores do Idiomas sem Fronteiras com a finalidade de orientar ou avaliar os tutores/professores.

\section{Como funcionam as avaliações?}

As avaliações também são realizadas de forma on-line, podendo ser divididas em habilidade escrita, habilidade de leitura, habilidade oral, etc. No caso do Japonês sem Fronteiras (JsF), por exemplo, as avaliações são feitas duas vezes por semestre, utilizando-se da plataforma Google Forms

\section{E se eu não souber manusear o aplicativo do curso síncrono on-line?}

No período de confirmação de inscrições no sistema do MEC, você será convocado pelo seu tutor/professor para receber uma sessão de orientação no próprio aplicativo. Dessa forma, poderá se familiarizar com o suporte tecnológico e com as ações disponibilizadas. Receberá importantes informações e poderá praticar já tendo uma base para iniciar seu curso síncrono on-line.

\section{Tenho deveres em um curso síncrono on-line?}

Sim. Seu professor trará informações importantes na primeira aula. É de suma importância que você se lembre que está em uma sala de aula, ainda que virtual. Assim, é importante que se posicione bem diante da câmera, focando em seu rosto, esteja sentado e de vestes apropriadas. Não é respeitoso nem para com o professor e nem para com os colegas que se alimente ou perturbe a aula de alguma forma. 
10.0 que não posso esquecer?

Nunca se esqueça que a aula é em tempo real. Professor e colegas estão diante dos computadores ao mesmo tempo que você. Deixe seu microfone fechado e abra apenas quando for utilizar. Em caso de emergência, feche sua imagem também. O chat poderá ser usado se quiser falar com todos ou especificamente com o professor ou algum colega de turma. Mantenha seu nome legível EM PORTUGUÊS em sua janela na tela. 